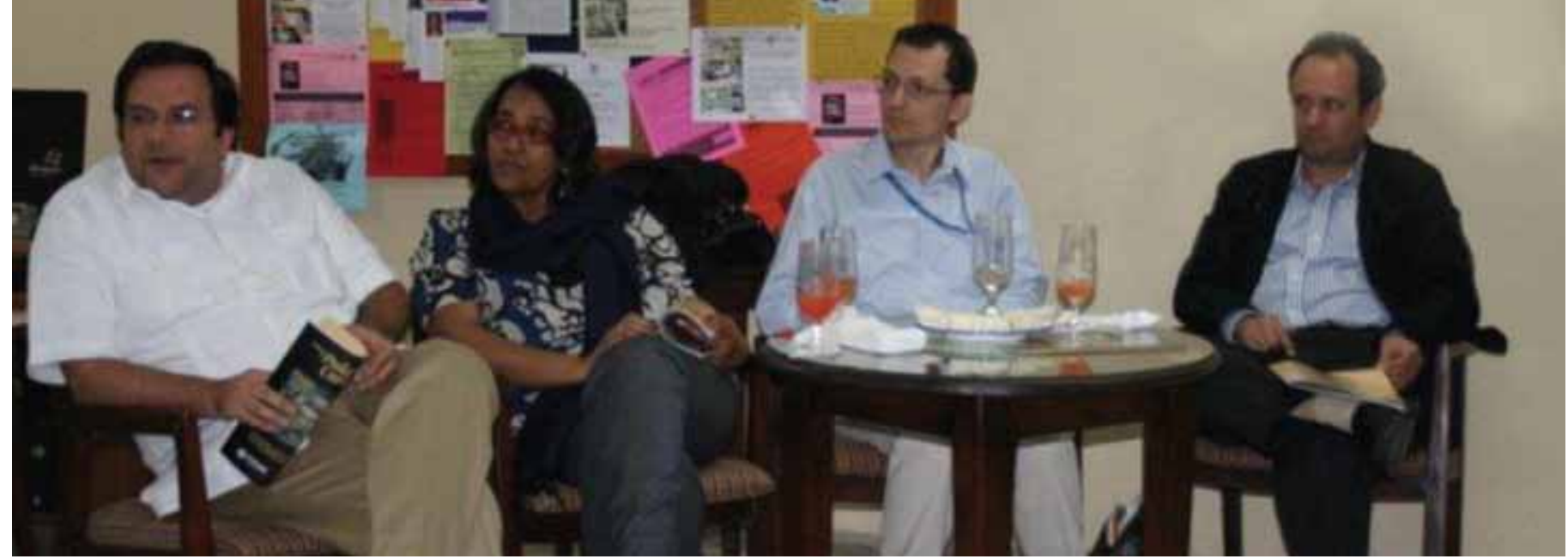

\title{
LA X PEÑA PEDAGÓGICA
}

Estos encuentros, de carácter informal entre el profesorado de la PUCMM, se organizan dos veces al año para compartir ideas y opiniones sobre los artículos del último ejemplar del Cuaderno de Pedagogía Universitaria. El tema anterior fue “Los Estudios Generales en el currículum universitario" y las reuniones se llevaron a cabo el 23 y el 31 de marzo de 2011, en Santiago y en Santo Domingo. A continuación reseñamos las ideas principales.

\section{Santiago}

La reunión comienza haciendo explícito el sentido de la convocatoria: una ocasión para discutir temas académicos y formar comunidad. Se recordó que la elección de la temática de los Estudios Generales partió de la ocasión de celebrarse en octubre del 2010 el II Simposio Internacional de Estudios Generales, en la PUCMM.

Uno de los articulistas comentó su propio texto. Marino Grullón primero recordó su experiencia como estudiante de Ingeniería en la UASD en los años setenta. La Educación Media de la época era tan buena, que él dominaba casi totalmente el contenido del primer año de la UASD. En el caso de su experiencia escribiendo el artículo, desde su posición de Vicerrector en aquel momento, él manifestó que el tema en la PUCMM es controversial. ¿Por qué? Básicamente por su falta de definición, que depende del contexto en que se desarrolla el programa. Cuando él entró en esta Institución, el Ciclo Básico buscaba lograr una formación integral y, al mismo tiempo, tratar de ambientar al estudiante al nuevo mundo universitario. Durante unos 12 años fue un programa independiente de las carreras. En el 1974 se integró a las carreras, en modalidad horizontal, es decir, el estudiante tiene que pasar el Ciclo Básico antes de entrar a asignaturas especializadas. Con el tiempo, se han introducido algunas asignaturas propias de la carrera. Así, el estudiante puede estar más seguro de su decisión vocacional, pues se le vincula desde el principio. Aunque en sus inicios, el Ciclo Básico era de carácter formativo, quedó siendo remedial, por el deterioro mismo de la educación dominicana. Sin embargo, el contexto de Santo Domingo es diferente en este sentido, el estudiante viene de otra plataforma académica, por lo que es conveniente considerar cómo se manejaría esta situación. Entonces, lo importante en esta Universidad con relación al Ciclo Básico de los Estudios Generales (que es su denominación original) es reflexionar sobre los cinco aspectos señalados al final del artículo (p. 24): El significado del término, sus objetivos, los criterios para su manejo, los componentes de la educación general y la viabilidad de las reformas en la PUCMM.
La próxima persona en hablar fue la Directora del Ciclo Básico, con la intención de continuar en la línea de la perspectiva desde la gestión institucional. Informó que recientemente se está llevando a cabo una serie de entrevistas con los directivos académicos y los docentes para recoger la percepción sobre el programa vigente. El informe de este trabajo, junto con la propuesta de reforma estará listo para el 10 de junio de este año.

Una de las docentes, de larga trayectoria en la PUCMM, comentó que cuando la Universidad reorganizó las Facultades, el Ciclo Básico adquirió otro enfoque y, más tarde, cuando se estipuló la titulación intermedia del nivel técnico (antes de la licenciatura), quedaba poco tiempo para las asignaturas del inicio. Poco a poco y por diferentes razones, se integraron cada vez más materias a las carreras. Pero el punto difícil radica en el equipo profesoral, que sea capaz de trascender los objetivos disciplinares de las asignaturas hacia una formación más integral.

El otro articulista presente, Jorge Tallaj, comentó sobre la asignatura Ciencia Ambiental, considerada en el Departamento de Ciencias Básicas como un ejemplo de educación integral. Está diseñada según competencias de Estudios Generales. Es electiva en el pensum de 5 carreras y reúne contenidos de Física, Biología y Química, en la búsqueda de fomentar un pensamiento interdisciplinar para problemas medioambientales. Sin embargo, a Jorge le preocupan otras dificultades: se enseña la matemática básica de la misma forma para el ingeniero que para el abogado. Es posible pensar en una matemática con un enfoque más interdisciplinario para el abogado, pero ¿qué hacer con la matemática para el ingeniero? Eso ameritaría problemas de gestión en la distribución de los grupos en el Ciclo Básico. Por otra pare, él comparte la idea de que el Ciclo Básico esté integrado al currículum de toda la carrera, pero es preciso buscar una solución al aspecto remedial del programa.

Un profesor, cuya formación universitaria fue en el extranjero, aportó lo siguiente: cada institución tiene una visión distinta de los Estudios Generales. En unos casos se da más énfasis a la filosofía y a las lenguas, por eso la reflexión sobre la educación general no es un tema acabado. En el caso dominicano, el Ciclo Básico necesita tener un carácter remedial, lo cual no se puede ignorar, pero tampoco significa dejarlo ahí. En este sentido, el profesor consideró conveniente compartir las vivencias de su propia formación. "Hice una carrera científico-tecnológica, pero con una fuerte tendencia hacia la filosofía y las artes liberales. Estos componentes de mi formación me llevaban a tener que reflexionar sobre temas éticos muy importantes y sobre 
cómo el pensamiento de las diferentes épocas y en la actualidad influía en el conocimiento científico. Eran temas ajenos a la disciplina que estudiaba, pero necesarios para construir argumentaciones sólidas. La formación general que recibí me ayudó a desarrollar herramientas mentales para analizar, para pensar con criterios."

La reunión terminó con la reflexión sobre la visión de la PUCMM de educar para el humanismo cristiano. Se hace más fácil hablar de materias como química y física, pero la formación humana en las carreras implica que los jóvenes aprendan a saber, a saber hacer y a saber ser, que son los tres pilares de la educación. Esta es una universidad apoyada en una encíclica, las preguntas son cómo hacer trascender esa preocupación a las aulas, con qué profesores contamos para ello y cómo, al mismo tiempo, debemos ayudar a estos profesores a través de su propia formación.

Asistentes a la Peña: Jorge Tallaj, Antonio Rivero y Lourdes Tapia, Ciencias Básicas; Lilian de Brens, Carmen Perez e Yngris Balbuena, Lingüística Aplicada; Maria Elizabeth Frómeta, Ciclo Básico; Juan Zapata, Educación; Jeffrey Perez, Administración; Rosemary Franquiz, Arquitectura; Rosario Corominas, Sandra Hernández y Nora Ramírez, Centro de Desarrollo Profesoral.

\section{En Santo Domingo}

La reunión inició con un profesor señalando que todos los articulistas tenían un punto de coincidencia: enfocaron los Estudios Generales desde el perfil del estudiante que inicia su itinerario universitario. Sin embargo, hay puntos de coincidencia en la formación del estudiante integral vs. el estudiante que se enfoca solo en su carrera. Ese último estudiante necesita una formación integral (humanista) a lo largo de toda su carrera.

Reaccionando a esto, una profesora expresó que la gran tarea de la Universidad es formar profesionales que sean ciudadanos. Ella hace referencia al Diplomado en Pedagogía Universitaria, que siempre enfatiza hacia la formación de profesionales sensibles y enfocados hacia la sociedad. Un reporte de la situación educativa de Finlandia pondera que su éxito ha sido porque han invertido en una formación integral. Por tanto, resulta contradictorio que la formación del currículo general sea un contrapeso a la educación especializada pues la primera le confiere sentido a la segunda. Existe una corriente de interés en la PUCMM sobre revalorizar los contenidos de los Estudios Generales, y en efecto, se ve diariamente en las aulas la necesidad de que esos contenidos sean fortalecidos, como en el área de letras. La revaloración de los Estudios Generales impactaría positivamente en la formación de los alumnos, en la formación de ellos como seres humanos.

"Es preocupante que todavía tengamos que convencernos de la importancia de los Estudios Generales", apuntaba otro profesor. En el último artículo se percibe una diferencia de tono en el enfoque de los Estudios Generales en Estados Unidos. En el ambiente norteamericano el tema se trata de forma exhaustiva y en el resto de los trabajos se aborda de forma defensiva y justificativa. Un elemento de discrepancia es ver los Estudios Generales como complemento de la formación profesional, por ejemplo "el médico que solo sabe de medicina, ni de medicina sabe". Constantemente, la carencia de elementos de carácter humano constituye un freno para el desarrollo profesional. No podemos ni siquiera alcanzar excelencia disciplinar con unos Estudios Generales débiles, esta cuestión es de una gran urgencia.

La reflexión grupal apuntó, entonces, hacia el sentido de los Estudios
Generales. Algunos docentes resaltaron que la revisión de la educación general implica un cambio, ya que está establecido que todas las carreras deben tener solo un $20 \%$ de educación general. Otros reconocen, sin embargo, que no hay nada que indique hacia dónde va o debe ir enfocada la tendencia de la educación general. ¿Es remedial? ¿Es propedéutica para las carreras? ¿O está dirigida a formar el ciudadano crítico que necesitamos? Hay horizontes no claros en este sentido, el enfoque en muchos casos es para tapar huecos y no para una formación humanística que invite a la sensibilidad social, al compromiso con la sociedad; la presión es hacia remediar lo que se recibe desde el bachillerato. La reflexión debe ir en la dirección de cuál es el propósito.

Una profesora manifestó que los Estudios Generales no deben ir hacia remediar, sino hacia formar un ciudadano ético, crítico, responsable. Lo que está en el fondo de todos esos artículos es cómo la universidad responde a los cambios que se dan fuera de ella. El Ciclo Básico responde a las deficiencias con que vienen los alumnos, en esa proyección la Universidad tiende a suplir las carencias de la Educación Media. Son interrogantes que vienen desde hace 5 a 10 años y a las que debemos responder ya.

"Al leer el ejemplar, en mí se dio una mezcla de alegría y de compromiso", apuntaba otro docente, pues esto nos dice lo que podemos hacer por estas nuevas generaciones y, también, por la conexión con las inquietudes del Centro de Desarrollo Profesoral de esta Institución y los planteamientos en el Diplomado en Pedagogía Universitaria que cursamos los docentes. Es excelente el artículo del perfil del docente. Plantea la idea de que el maestro no está acabado. A este profesor le llamaron la atención los tres ámbitos mencionados en la p. 17: la parte institucional, la del curriculum y el perfil del docente. El reto también conlleva el perfil del alumno que nos llega.

Se hizo una invitación de que al seguir la discusión sobre el tema se tocara lo que son las asignaturas que integran los Estudios Generales. Una docente indicó que el programa debe ser más interactivo, que se conectaran las materias que dan esos profesores con las propias. Habría que sugerir otras asignaturas para el área de Ética. Lo que está claro es que tenemos que estar todos viendo hacia el mismo lado, con las mismas voces y el mismo propósito.

Otras reflexiones a desarrollar: la del concepto de Educación Superior desde la Universidad, "todos fuimos fruto de un Ciclo Básico que fue remedial". El tiempo presente demanda otro espacio, hay que empezar a ser provocador, desafiante en la formación. El profesorado es sensible a este tema, pero así como los estudiantes ven que no son pertinentes determinadas materias, esa misma concepción la tienen algunos profesores. Si los profesores no encuentran el sentido y el valor que tiene la asignatura que imparten, no van a entender qué es la materia en realidad. Hay que trabajar a nivel curricular, a nivel de profesores, a nivel institucional. Quizás todo el diseño de los Estudios Generales se debe conformar en una unidad para que se vea que tienen relación con el conjunto. Necesitamos una concepción más sistémica.

Asistentes a la Peña: Celeste Aquino y Mayra Muñoz, Lingüística Aplicada; Olson Ortíz, Ingeniería Telemática; Rodrigo Orizondo, Ingeniería de Sistemas y Cómputos; Luisa Taveras, Ciclo Básico; Félix María Peña, Derecho; Geovanny Rosado y Sara Güílamo, Psicología; Alfredo Capellán, Comunicación Social; Oliva Hernando y Luis Peña, Centro de Desarrollo Profesoral. 